\title{
Treatment of venous thromboembolism - effects of different therapeutic strategies on bleeding and recurrence rates and considerations for future anticoagulant management
}

\author{
Bastian Hass ${ }^{1 *}$, Jayne Pooley ${ }^{2}$, Adrian E Harrington ${ }^{2}$, Andreas Clemens ${ }^{3,4}$ and Martin Feuring ${ }^{3}$
}

\begin{abstract}
Effective treatment of venous thromboembolism (VTE) strikes a balance between prevention of recurrence and bleeding complications. The current standard of care is heparin followed by a vitamin $\mathrm{K}$ antagonist such as warfarin. However, this option is not without its limitations, as the anticoagulant effect of warfarin is associated with high inter- and intra-patient variability and patients must be regularly monitored to ensure that anticoagulation is within the narrow target therapeutic range. Several novel oral anticoagulant agents are in the advanced stages of development for VTE treatment, some of which are given after an initial period of heparin treatment, in line with current practice, while others switch from high to low doses after the initial phase of treatment. In this review we assess the critical considerations for treating VTE in light of emerging clinical data for new oral agents and discuss the merits of novel treatment regimens for patients who have experienced an episode of deep vein thrombosis or pulmonary embolism.
\end{abstract}

Keywords: Venous thromboembolism, Anticoagulants, Vitamin K antagonists, Heparin, Recurrence, Bleeding

\section{Review}

Vitamin $\mathrm{K}$ antagonists (VKAs) such as warfarin have been the mainstay of treatment and secondary prevention of venous thromboembolism (VTE) for many years, and are recognised by international guidelines as the current standard of care. VKAs usually establish an anticoagulant effect within 2-3 days of administration. However, because a rapid, intensive anticoagulant effect is required, a quicker acting agent such as heparin is used initially until the desired anticoagulant effect of the VKA has been achieved. Guidelines on the management of VTE recommend that administration of heparin is started concomitantly with a VKA and discontinued after 5 days or more, once the international normalised ratio (INR) has been between 2.0 and 3.0 for 2 consecutive days [1].

\footnotetext{
*Correspondence: bastian.hass@boehringer-ingelheim.com 'Boehringer Ingelheim GmbH, Binger Strasse 173, 55216, Ingelheim am Rhein, Germany

Full list of author information is available at the end of the article
}

Despite the benefits offered by oral therapy, the anticoagulant effect of VKA treatment is associated with significant inter- and intra-patient variability, leading to unpredictable results in clinical practice. In addition, VKAs have an unpredictable dose-response relationship. Furthermore, regular intensive blood monitoring is required to ensure that the INR is maintained within the target therapeutic range (INR 2.0-3.0); under-anticoagulation can result in recurrent thromboembolism, while over-anticoagulation increases the risk of bleeding. Achieving a balance between the risk of recurrence and bleeding complications is therefore a central consideration in VTE management.

Several novel, oral anticoagulants are in development, including dabigatran etexilate (dabigatran; a reversible direct thrombin inhibitor) and the factor Xa inhibitors apixaban, edoxaban and rivaroxaban. These anticoagulants could provide a more predictable alternative to VKAs and have the potential to change the recommended standard for treatment of VTE. 


\section{What is known about the rate of VTE recurrence in patients treated with the currently-recommended therapeutic agents?}

Data on the frequency of early recurrence of VTE (i.e., within 5 days of treatment initiation) are sparse and associated with broad confidence intervals [2]. However, clinical trials and patient registries have consistently demonstrated that the rate of VTE recurrence is highest immediately after the initial event and gradually decreases over time (Figure 1) [3-5]. In one analysis of recurrent VTE timing among 1021 patients with deep vein thrombosis (DVT) or pulmonary embolism (PE) who received heparin plus warfarin, there was a clustering of episodes within the first $2-3$ weeks after treatment initiation [6]:

- $26 \%$ occurred within 7 days (cumulative incidence $1.5 \%)$

- $57 \%$ within 14 days (cumulative incidence $3.2 \%$ )

- $72 \%$ within 21 days (cumulative incidence $4.1 \%$ )

Cumulative incidence of recurrence in these patients reached a plateau of $6 \%$ at 3 months [6].

In a meta-analysis of 18 studies that addressed the timing of recurrent VTE in patients who were continuously treated with VKAs for 1-6 months after their first thromboembolic event, the incidence of recurrence stabilised approximately 9 months after the index event and appeared to be independent of the duration of anticoagulant therapy [7].

The optimal duration of anticoagulant therapy is controversial. According to the American College of Chest Physicians (ACCP) guidelines, the risk of recurrence after stopping therapy is largely determined by two factors; whether the acute episode of VTE has been effectively treated and the patient's intrinsic risk of having a new episode [1]. Patients with reversible provoking risk factors for VTE (major factors such as surgery, hospitalisation or plaster cast immobilisation, or minor factors such as oestrogen therapy, pregnancy or prolonged travel, prior to the acute episode) clearly benefit from anticoagulation for 3 months rather than shorter durations. The guidelines identify unprovoked VTE and active cancer as the most important risk factors for recurrence after stopping anticoagulant therapy and patients in these categories should generally receive longer durations of thromboprophylaxis. It is recommended that the risk-to-benefit ratio of continuing longterm anticoagulant therapy is assessed periodically in the individual patient [1].

The pattern of recurrence following a first unprovoked VTE is different in men and women. In a meta-analysis of prospective studies of patients with a first VTE who received standardised anticoagulant treatment, among the patients with an unprovoked VTE, men were at significantly higher risk of recurrence than women (hazard ratio [HR] 2.2, 95\% confidence interval [CI] 1.7, 2.8) [8].

It appears that the risk of developing recurrent VTE is not related to the type of initial thromboembolic event (i.e., DVT or PE). A systematic review showed that the overall risk of a recurrent thromboembolic event was not significantly different between patients presenting with PE or DVT. It is therefore unlikely that the distribution of recurrent events would be different between these two groups of patients [9]. Analysis of patients in the Worcester Venous Thromboembolism Study found that those who presented with PE or isolated DVT experienced similar rates of subsequent $\mathrm{PE}$ and overall VTE in the 3 -year follow-up (5.9\% vs. $5.1 \%$ and $15.0 \%$ vs. $17.9 \%$, respectively) [10]. However, the risk of early mortality from VTE (i.e., within 1 month) is much greater after presenting with PE than DVT [11].

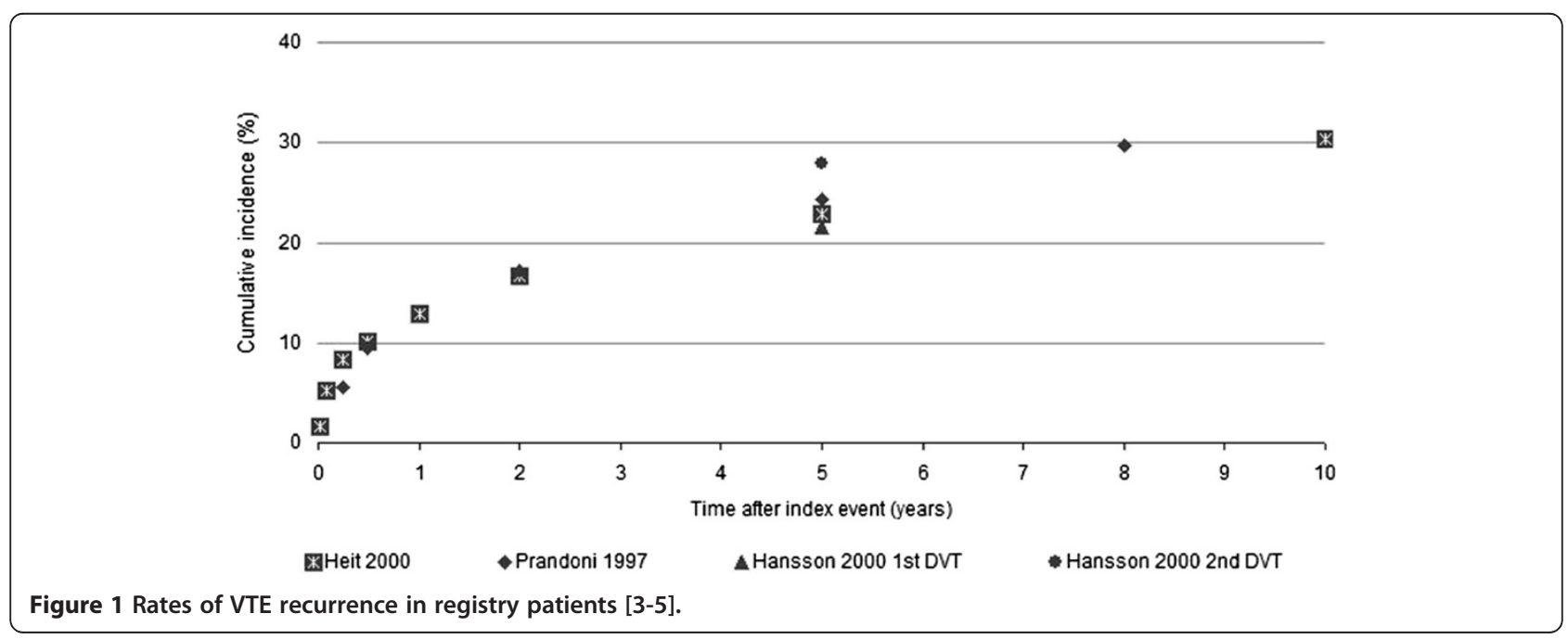


Furthermore, recurrent episodes of VTE are approximately three times more likely to be PE after an initial PE ( 60\%) than after an initial DVT ( 20\%) [11,12]. This difference may justify more aggressive initial treatment for patients presenting with PE [1].

\section{How do bleeding rates vary in patients treated with currently recommended therapeutic agents?}

Bleeding is the primary complication of anticoagulant therapy. In the earlier (placebo-controlled) trials in patients with VTE or atrial fibrillation, major bleeding occurred in approximately $1-1.5 \%$ of patients per year during 3-12 months of VKA therapy compared with 0.6-1\% for controls. Rates of intracranial haemorrhage (ICH) were $0.3 \%$ and $0.1 \%$, respectively. Thus, it is estimated that treatment with VKAs increases the risk of major bleeding by $0.3-0.5 \%$ per year and of $\mathrm{ICH}$ by approximately $0.2 \%$ per year compared with controls [13-15]. However, higher major bleeding rates of $2-4 \%$ per year have been reported during longer-term trials of VKAs in patients with VTE [15-17]. In the VKA treatment arms of recent clinical trials of VTE treatment or secondary prevention, approximately of $2 \%$ of patients experience major bleeding [18-22]. Recent trials in patients with atrial fibrillation show rates of $\mathrm{ICH}$ of $0.7-$ $0.8 \%$ per year with VKA therapy [23-25].

The choice of heparin formulation, i.e., subcutaneous weight-adjusted unfractionated heparin (UFH) or lowmolecular-weight heparin (LMWH), has no observed effect on the frequency of major bleeding [26,27]. Several studies of VTE-treated patients have also shown a clustering of bleeding events at the start (i.e., during the initial 3 months) of anticoagulant therapy [6,28-30]. This is consistent with the hypothesis that patients with a predisposition to bleeding are more likely to develop this complication soon after anticoagulant initiation [30].

Due to their selective nature, clinical trials may, however, underestimate the frequency of bleeding, and the incidence of bleeding is markedly greater in clinical practice. The Worcester VTE study, a large US community-based trial, showed major bleeding rates of $12-13 \%$ per year, and the cumulative incidence of major bleeding was approximately $8 \%$ in the month following initial diagnosis of VTE [31].

\section{What are the consequences of anticoagulant-related bleeding?}

The clinical impact of anticoagulant-related bleeding complications is often severe; as many as $11 \%$ of major bleeding episodes are fatal within 3 months [32]. Among 17,368 patients with VTE enrolled on the Registry of Patients with Venous Thromboembolism (RIETE), 2.3\% developed major bleeding during the first 3 months of therapy [33]. Of those patients with bleeding episodes,
$5.9 \%$ re-bled within 30 days, all at the same site as the first episode. Furthermore, 33\% died within 30 days of major bleeding, with the majority of deaths due to bleeding [33]. In a meta-analysis of trials with more than 6 months' follow-up, the case-fatality rate for major bleeding was $13.4 \%$; for intracranial bleeding, $45.8 \%$ of episodes were fatal [30].

Bleeding episodes during anticoagulant therapy are also associated with decreased quality of life and increased resource utilisation and costs. In a randomised controlled trial of warfarin for the prevention of stroke in non-rheumatic atrial fibrillation, patients taking warfarin who had a bleeding episode had significantly lower scores on a summary health perceptions index ( $\mathrm{p}<$ 0.05), and significantly higher scores for health concern and health distress $(\mathrm{p}<0.05)$ compared with patients who did not bleed [34]. Furthermore, in a model of the costs of acute DVT treatment, minor bleeding complications were assumed to result in 1 additional day of hospitalisation and physician services for subsequent hospital care, at a cost of \$499 [35].

\section{What factors are associated with unfavourable outcomes among patients with VTE?}

Many studies have investigated the factors associated with an increased risk of VTE recurrence. The most strongly implicated are active cancer, increased plasma fibrin D-dimer, male sex, increasing patient age, increasing body mass index, lupus anticoagulant, antiphospholipid antibody, and protein $\mathrm{C}$ or protein $\mathrm{S}$ deficiency [4,16,36-41]. Moreover, patients who experience a recurrence of VTE during VKA therapy have a worse prognosis (i.e., increased incidence of further recurrences and bleeding) than those with new VTE or those who suffered recurrence after termination of VKA therapy.

The major determinants of VKA-induced bleeding are the intensity of the anticoagulant effect, patient characteristics, concomitant use of drugs that interfere with haemostasis and length of therapy [15]. In a multivariate analysis of the RIETE registry, age $>75$ years, recent bleeding, cancer, creatinine levels $>1.2 \mathrm{mg} / \mathrm{dL}$, anaemia, or PE at baseline were independently associated with an increased risk for major bleeding, but type or number of concomitant antithrombotic agents received were not [42]. When risk profiles were derived by assigning scores to these factors, the incidences of major bleeding in the first 3 months of therapy were $0.3 \%, 2.6 \%$ and $7.3 \%$, in low-, medium- and high-risk patients, respectively [42].

In patients receiving anticoagulant therapy, those with cancer have an increased risk of bleeding complications compared with patients without cancer [43-46]. In one study that evaluated outcomes in 842 patients with VTE who were treated with heparin and VKAs, 181 of whom had cancer, the 12-month cumulative incidence of major 
bleeding in patients with cancer was more than twice that of patients without cancer (HR, 2.2; 95\% CI 1.2, 4.1). Moreover, the frequency of major bleeding correlated with the severity of the malignancy [45]. The incidence of bleeding also varies according to the site of cancer $[45,46]$, with one study showing that genitourinary cancers were most strongly associated with major bleeding (HR, 4.5; 95\% CI 2.1, 9.9) [45].

In patients with impaired renal function, LMWH (which is mainly cleared by the kidneys) may bioaccumulate and cause bleeding, although the evidence for excluding patients with renal insufficiency is controversial. Moreover, it has been reported that the risk of major bleeding in patients with impaired renal function is increased with both LMWH and UFH [47].

\section{How do anticoagulant strategies differ in high-risk patient populations?}

Patients with cancer represent a population at particularly high risk for VTE. Cushman et al. found the firstyear incidence of recurrent VTE in the general VTE population was $7.7 \%$, compared with $14.0 \%$ in patients with cancer [37]. Among patients enrolled in the RIETE registry, those with cancer had an increased incidence of recurrent VTE (11.4\% vs $2.1 \%$; $\mathrm{p}<0.001)$, major bleeding $(5.1 \%$ vs. $2.1 \% ; \mathrm{p}=0.007)$ and mortality $(20 \%$ vs $5.4 \% ; \mathrm{p}<0.001)$, compared with patients without cancer [48].

Management of cancer patients with VKAs can be challenging because of the frequent use of chemotherapy and other drugs that may affect INR control and increase bleeding risk through induced thrombocytopenia, in addition to increasing the risk of liver dysfunction [49]. To determine whether outcomes in VTE patients with cancer were better with LMWH monotherapy or VKAs, a meta-analysis of five open-label secondary prevention trials was performed (two each of 3 and 6 months' duration, one unspecified). The pooled risk ratio for VTE recurrence in patients treated with LMWH was $0.53(95 \%$ CI $0.36,0.76 ; p=0.007)$ and the pooled relative risk for major bleeding was 0.98 (95\% CI $0.49,1.93 ; \mathrm{p}=0.95$ ) [49]. The American Society of Clinical Oncology guidelines recommend the use of LMWH monotherapy in patients with cancer who experience VTE, for both initial (5-10 days) and long-term $(\geq 6$ months) treatment [50].

There is also clinical interest in an effective and predictable treatment regimen for patients with more severe VTE (e.g. acute PE), that removes the need for laboratory monitoring associated with VKAs and minimises bleeding complications. Mortality from recurrent VTE is 2- to 3-fold greater after PE than DVT [9,51]. In a study of patients with acute symptomatic PE (cancer patients excluded), the hospital length of stay was shorter in patients on LMWH monotherapy compared with those receiving warfarin, although for VTE recurrence, death, bleeding episodes or a composite of the three, there were no significant differences between treatment groups [52].

\section{How does treatment with novel oral anticoagulants deviate from the established treatment paradigm?}

Novel oral anticoagulants including apixaban, dabigatran, edoxaban and rivaroxaban can be grouped into two categories depending on the VTE treatment regimens used in clinical trials.

In trials of dabigatran, patients began treatment with heparin in addition to warfarin (or warfarin-placebo) for at least 5 days, until the patient's INR or sham INR reached therapeutic levels for 2 consecutive days, at which point dabigatran was initiated at a dose of $150 \mathrm{mg}$ twice daily (bid) [21,22]. Similarly, ongoing studies of edoxaban begin oral administration of $60 \mathrm{mg}$ once daily (qd) following initial heparin treatment once a stable therapeutic INR has been achieved with warfarin [53].

In the cases of rivaroxaban and apixaban, oral therapy is initiated without concomitant heparin. In the EINSTEIN trials, patients began treatment with $15 \mathrm{mg}$ rivaroxaban bid, reduced to $20 \mathrm{mg}$ qd after 3 weeks $[18,19]$. A similar strategy is used in the AMPLIFY trial, where the dose of apixaban is reduced from $10 \mathrm{mg}$ bid to $5 \mathrm{mg}$ bid after 7 days [54].

\section{What are the rates of bleeding and recurrence in patients treated with novel oral anticoagulants?}

Data published to date suggest that initiation of treatment with heparin has a crucial role to play in minimising the early rate of VTE recurrence. In a study that compared treatment with the pentasaccharide idraparinux with standard therapy (i.e., heparin followed by VKA) in patients with acute PE, the rates of VTE recurrence during the first 2 weeks of treatment favoured standard therapy [55]. This effect was maintained throughout the study; the odds ratio for recurrence by day 92 was 2.14 ( $95 \%$ CI 1.21, 3.78), suggesting that initial heparin treatment may have a durable protective effect [55]. Results from recent trials of rivaroxaban, where initiation of treatment with heparin did not occur $[18,19]$, are challenging this concept, though the evidence is still too scarce to be conclusive.

Recurrence rates reported in phase III clinical trials of novel oral anticoagulants for patients presenting with acute VTE are shown in Table 1. Overall, the incidence of VTE recurrence in these studies is low and not significantly different from that in the comparator LMWH plus VKA arms - typically $2-3 \%$ at 3 months. The cumulative risk of VTE recurrence in patients presenting with DVT and/or PE over time was similar for LMWH plus dabigatran and LMWH plus warfarin in the RE- 
Table 1 Rates of recurrent VTE and bleeding reported in clinical studies of novel oral anticoagulants

\begin{tabular}{|c|c|c|c|c|c|c|}
\hline \multirow[t]{2}{*}{ Study } & \multirow{2}{*}{$\begin{array}{l}\text { Patients, } \\
\text { N }\end{array}$} & \multirow{2}{*}{$\begin{array}{l}\text { Treatment } \\
\text { duration }\end{array}$} & \multirow[t]{2}{*}{ Rate of VTE recurrence } & \multicolumn{3}{|l|}{ Rate of bleeding } \\
\hline & & & & Major bleeding & All bleeding & Major/CRNM bleeding \\
\hline $\begin{array}{l}\text { Schulman } 2009 \\
\text { RE-COVER [21] }\end{array}$ & 2564 & 6 months & 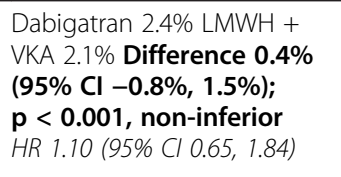 & $\begin{array}{l}\boldsymbol{a}^{\boldsymbol{a}} \text { Dabigatran } 1.6 \% \mathrm{LMWH}+\mathrm{VKA} \\
1.9 \% \text { HR } 0.82 \\
(95 \% \mathrm{Cl} 0.45,1.48)\end{array}$ & $\begin{array}{l}\text { Dabigatran 16.1\%LMWH + } \\
\text { VKA 21.9\% HR 0.71 }(95 \% \mathrm{Cl} \\
0.59,0.85)\end{array}$ & $\begin{array}{l}{ }^{b} \text { Dabigatran } 5.6 \% \text { LMWH + } \\
\text { VKA 8.8\% HR } 0.63(95 \% \mathrm{Cl} \\
0.47,0.84) ; p=0.002\end{array}$ \\
\hline $\begin{array}{l}\text { Schulman } 2011 \\
\text { RE-COVER II [22] }\end{array}$ & 2568 & 6 months & $\begin{array}{l}\text { Dabigatran 2.4\% LMWH + } \\
\text { VKA 2.2\% Difference 0.2\% } \\
\text { (95\% CI -1.0\%, 1.5\%); } \\
\text { p < 0.0001, non-inferior } \\
H R 1.08 \text { (95\% Cl } 0.64,1.80)\end{array}$ & $\begin{array}{l}\boldsymbol{a}^{a} \text { Dabigatran } 1.2 \% \mathrm{LMWH}+\mathrm{VKA} \\
1.7 \% \text { HR } 0.69 \\
(95 \% \mathrm{Cl} 0.36,1.32)\end{array}$ & $\begin{array}{l}\text { Dabigatran 15.6\% LMWH + } \\
\text { VKA 22.1\% HR 0.67 (95\% Cl } \\
0.56,0.81)\end{array}$ & \\
\hline $\begin{array}{l}\text { EINSTEIN Investigators } 2010 \\
\text { EINSTEIN-DVT [18] }\end{array}$ & 3451 & $\begin{array}{l}3,6 \text { or } 12 \\
\text { months }\end{array}$ & $\begin{array}{l}\text { Rivaroxaban } 2.1 \% \text { LMWH + } \\
\text { VKA } 3.0 \% \\
\mathbf{p}<\mathbf{0 . 0 0 1} \text {, non-inferior } \\
\text { HR } 0.68(95 \% \text { Cl } 0.44,1.04)\end{array}$ & $\begin{array}{l}\text { c Rivaroxaban 0.8\% LMWH + VKA } \\
1.2 \% \text { HR } 0.65(95 \% \text { Cl 0.33, 1.30); } \\
p=0.21\end{array}$ & & $\begin{array}{l}{ }^{\boldsymbol{d}} \text { Rivaroxaban } 8.1 \% \mathrm{LMWH}+ \\
\text { VKA 8.1\% HR } 0.97(95 \% \mathrm{Cl} \\
0.76,1.22) ; \mathrm{p}=0.77\end{array}$ \\
\hline $\begin{array}{l}\text { EINSTEIN-PE Investigators } 2012 \\
\text { EINSTEIN-PE [19] }\end{array}$ & 4832 & $\begin{array}{l}3,6 \text { or } 12 \\
\text { months }\end{array}$ & $\begin{array}{l}\text { Rivaroxaban } 2.1 \% \mathrm{LMWH}+ \\
\text { VKA } 1.8 \% \\
\mathbf{p}=\mathbf{0 . 0 0 3}, \text { non-inferior } H R \\
1.12(95 \% \mathrm{Cl} 0.75,1.68)\end{array}$ & $\begin{array}{l}{ }^{c} \text { Rivaroxaban } 1.1 \% \text { LMWH + VKA } \\
2.2 \% \\
\text { HR } 0.49(95 \% \mathrm{Cl} 0.31,0.79) ; p=0.003\end{array}$ & & $\begin{array}{l}\boldsymbol{d}^{\boldsymbol{}} \text { Rivaroxaban } 10.3 \% \mathrm{LMWH}+ \\
\text { VKA } 11.4 \% \mathrm{HR} 0.90(95 \% \mathrm{Cl} \\
0.76,1.07) ; p=0.23\end{array}$ \\
\hline \multicolumn{7}{|c|}{$\begin{array}{l}\text { CRNM, clinically relevant non-major; HR, hazard ratio; LMWH, low molecular weight heparin; VKA, vitamin } \mathrm{K} \text { antagonist. } \\
\text { a: Bleeding defined as major if clinically overt and if it was associated with a fall in the haemoglobin level of at least } 20 \mathrm{~g} / \mathrm{L} \text {, resulted in the need for transfusion of } 2 \text { or more units of red cells, involved a critical site or } \\
\text { was fatal. } \\
\text { b: Clinically relevant non-major bleeding was defined as bleeding not meeting the criteria for major bleeding but associated with spontaneous skin haematoma of at least } 25 \mathrm{~cm}^{2} \text {, spontaneous nose bleed of more } \\
\text { than } 5 \text { minutes' duration, macroscopic haematuria (spontaneous or, if associated with intervention, lasting more than } 24 \text { hours), spontaneous rectal bleeding (more than spotting on toilet paper), gingival bleeding for } \\
\text { more than } 5 \text { minutes, bleeding leading to hospitalisation and/or requiring surgical treatment, bleeding leading to a transfusion of less than } 2 \text { units of whole blood or red cells, or any other bleeding considered } \\
\text { clinically relevant by the investigator. } \\
\text { c: Bleeding was defined as major if it was clinically overt and associated with a fall in the haemoglobin level of } 20 \mathrm{~g} / \mathrm{L} \text { or more, or if it led to transfusion of two or more units of red cells, or if it was retroperitoneal, } \\
\text { intracranial, occurred in a critical site or contributed to death. } \\
\text { d: Clinically relevant non-major bleeding was defined as overt bleeding not meeting the criteria for major bleeding but associated with medical intervention, unscheduled contact with a physician, interruption or } \\
\text { discontinuation of study treatment, or associated with any other discomfort such as pain or impairment of activities of daily life. }\end{array}$} \\
\hline
\end{tabular}


COVER and RE-COVER II studies [21,22]. In the EINSTEIN studies, rivaroxaban was non-inferior to standard therapy in terms of cumulative recurrence of VTE in patients presenting with DVT and in patients presenting with PE $[18,19]$. No data on the recurrence rates in patients treated with edoxaban or apixaban are available, although studies are ongoing.

According to a meta-analysis of selected trials of dabigatran etexilate, there was a higher incidence of acute coronary syndrome (ACS) or myocardial infarction (MI) events in the dabigatran arms compared with the control arms; however, the trials included several doses, comparators, indications and treatment durations [56]. These findings were mainly driven by the large RE-LY trial in patients with atrial fibrillation in which there were numerically, but not statistically significantly, fewer MIs with warfarin compared with dabigatran. ACS events were also more frequent (but still $<1 \%$ ) with dabigatran than with warfarin in a trial of secondary prevention of VTE, whereas there was no difference between dabigatran and placebo during extended maintenance therapy after VTE [57,58]. In addition, no signal for increased ACS events was detected with dabigatran versus enoxaparin in pooled trials of primary VTE prevention in patients after total hip or knee replacement [59]. This suggests that the difference seen in the warfarincontrolled studies may be due to a more protective effect of warfarin rather than an adverse effect of dabigatran. In the VTE treatment trials, the incidences of ACS events in the dabigatran and standard therapy groups, respectively, were $0.3 \%$ versus $0.2 \%$ in RE-COVER and $0.4 \%$ versus $0.1 \%$ in RE-COVER II $[21,22]$. In the EINSTEIN-PE study, incidences of ACS were $0.6 \%$ with rivaroxaban versus $0.9 \%$ with standard therapy [19].

Reported rates of bleeding complications in clinical trials for the novel oral agents in development are also shown in Table 1. Dabigatran was associated with similar major bleeds, and significantly fewer episodes of any bleeding compared with warfarin in the RE-COVER study [21]. A similar pattern was observed in the RECOVER II study [22]. These findings are consistent with previous data from phase III studies of dabigatran, such as the RE-LY trial [23]. In the EINSTEIN-DVT trial, there was no significant difference between rivaroxaban and warfarin regarding the rate of the primary safety endpoint (the composite of major or clinically relevant non-major bleeding), or in the incidence of major bleeding [18]. In EINSTEIN-PE, fewer major bleeding events were observed with rivaroxaban than with standard therapy, although there was no significant difference between treatment groups in terms of the composite of major or clinically relevant non-major bleeding [19]. Without a direct comparative trial of the new oral anticoagulants with consistent definitions of bleeding and
VTE recurrence and independent assessments of all endpoints it is not valuable, and would have to be interpreted with significant caution, when attempting to determine whether one drug is more effective or safe than another.

\section{What does the available evidence mean for the future treatment of VTE?}

To date, initial heparin followed by VKA has shown the greatest benefit in reducing the rate of recurrent VTE. This regimen therefore represents the current gold standard against which any new treatment will be assessed. However, several studies have shown that many patients experience under- or over-anticoagulation while on VKA therapy, putting them at risk of recurrent VTE or bleeding, respectively. A recent study of discharge records for patients in the United States hospitalised with an index VTE found that $19.8 \%$ had no INR monitoring and for those who were monitored only $38.1 \%$ of INR values were within the therapeutic range (INR 2.0-3.0) [60]. In recent clinical trials, the time patients receiving warfarin spent in the therapeutic range is $58 \%$ in EINSTEIN-DVT and 60\% in RE-COVER and the level of anticoagulation in these patients at any given point in the therapy is subject to uncertainty.

There is a lack of information from patients receiving anticoagulation for VTE treatment in real-world settings. Therefore we provide some information from other patient groups with the caveat that they do not translate directly to patients with VTE. Several publications indicate that, although good levels of anticoagulation control can be achieved in routine practice $[61,62]$, this is not universal. For example, time in therapeutic range among atrial fibrillation patients was $42.1 \%$ in 'usual care' (outside of specialist anticoagulation clinics) [63], and was 48.7\% during the first 3 months of therapy after heart valve surgery in a retrospective cohort prior to implementing a trial of an aggressive warfarin dosing algorithm' [64]. Further to this, registry studies of VKA use demonstrate that only about $50 \%$ of atrial fibrillation patients at moderate or high risk of stroke actually receive treatment with a VKA. Reasons cited by physicians for not prescribing warfarin included previous haemorrhage (including ICH) while taking warfarin, falls and patient refusal or history of non-adherence $[65,66]$.

Consideration of clinical trial data on heparin plus VKA should also take into account the likelihood that anticoagulation use and control may be poorer in realworld settings. Simply put, it is probable that event rates reported in the heparin plus VKA arms of clinical trials overestimate the potential performance in clinical practice. Additionally, the population of patients prescribed VKAs will be less homogeneous than the carefully selected clinical trial population, including a proportion who will be VKA-naïve, and thus less likely to 
experience good control after starting VKAs in clinical practice. While some of the factors potentially contributing to poorer anticoagulation usage, adherence and control in clinical practice compared with clinical trials may apply equally to the novel oral anticoagulants and to conventional therapy, others might be expected to apply more strongly to the outcomes of conventional therapy, namely those factors deriving from the complexity of optimally managing VKA therapy. In this context, demonstration of non-inferiority versus heparin plus VKA in studies of novel agents could be indicative of potentially improved outcomes in patients treated with these drugs compared with warfarin in clinical practice. However, there are currently no data available to evaluate this.

Dabigatran etexilate has been available for clinical use for longer than rivaroxaban. As expected with a new anticoagulant, several case reports of serious bleeding in patients with atrial fibrillation who were taking dabigatran have been published. However, a recent review of post-approval safety data by the European Medicines Agency found that the frequency of reported fatal bleedings with dabigatran was significantly lower than had been observed in clinical trials at the time of authorisation [67]. A US Food and Drug Administration safety analysis concluded that dabigatran, used in patients with atrial fibrillation, did not increase the risk of bleeding compared to warfarin, and found that the combined incidence of ICH and gastrointestinal bleeding for new users of warfarin was higher than for new dabigatran users [68]. In an observational real-world study, the efficacy and safety data for dabigatran in patients who had undergone total hip or knee replacement were also supportive of the phase III trial results [69].

Bleeding complications represent the primary safety concern for physicians treating patients with VTE. To date, data are failing to identify significant differences in bleeding rates in subgroups of patients who may respond better to alternative treatment strategies. Data are also scarce for patients at the extreme end of the spectrum with the most severe VTE (i.e., PE). Moreover, there remains a need to develop an effective method of linking patient bleeding risk profiles with a range of therapeutic options. Additional study data will help to differentiate the risks and benefits of the different anticoagulants and might enable identification of VTE patient subgroups that could benefit from alternative treatments.

The risks of VTE recurrence and bleeding are highest in the first weeks of treatment, which underscores the need to achieve the optimal level of anticoagulation in this crucial phase. Regardless of the treatment strategy, physicians must aim to achieve an optimal balance between efficacy and safety. A novel anticoagulant that demonstrates comparable efficacy in terms of VTE prevention compared with the standard of care, but may also minimise bleeding complications, has the potential to change current medical practice for the treatment of VTE.

\section{Conclusions}

Novel oral anticoagulants have demonstrated safety and efficacy in clinical trials and could provide physicians and patients with DVT or PE more convenient therapeutic options. In clinical trials, on the key clinical outcomes of VTE recurrence and bleeding, these new agents perform similarly to the established standard of care, i.e., heparin plus VKA. However, in real-world settings, novel agents could produce better patient outcomes.

Some novel agents, such as rivaroxaban and apixaban, are initiated at higher doses without heparin, but clinical trial data have yet to confirm which patient populations are likely to derive more or less benefit from this alternative approach, especially in the first 2 weeks of treatment. The established treatment regimen - initial use of heparin followed by an oral anticoagulant - may well remain the standard of care in certain high-risk populations. However, it remains to be seen which approach will lead to the greatest improvements in clinical outcomes in the treatment and secondary prevention of VTE.

\section{Abbreviations}

ACCP: American College of Chest Physicians; ACS: Acute coronary syndrome; Bid: Twice daily; Cl: Confidence interval; CRNM: Clinically relevant non-major; DVT: Deep vein thrombosis; HR: Hazard ratio; ICH: Intracranial haemorrhage; INR: International normalised ratio; LMWH: Low-molecular-weight heparin; MI: Myocardial infarction; PE: Pulmonary embolism; QD: Once daily; UFH: Unfractionated heparin; VKA: Vitamin K antagonist; VTE: Venous thromboembolism.

\section{Competing interests}

$\mathrm{BH}, \mathrm{AC}$ and MF are employees of Boehringer Ingelheim. JP and AEH are employees of United BioSource Corporation. The authors declare that they have no competing interests.

\section{Authors' contributions}

$\mathrm{BH}$ conceived the review, contributed to planning and drafting, and reviewed the manuscript. JP drafted, edited and reviewed the manuscript. AEH carried out literature searches, drafted and edited the manuscript. AC contributed editorial direction and reviewed the manuscript. MF reviewed the clinical data presented in the manuscript and contributed editorial guidance. All authors read and approved the final manuscript.

\section{Acknowledgements}

Editorial and writing assistance was provided by Elena Garonna of PAREXEL, with funding from Boehringer Ingelheim.

\section{Author details}

${ }^{1}$ Boehringer Ingelheim GmbH, Binger Strasse 173, 55216, Ingelheim am Rhein, Germany. ${ }^{2}$ United BioSource Corporation, River House, 33 Point Pleasant, London SW18 1NN, UK. 3Boehringer Ingelheim Pharma GmbH \& Co. KG, Binger Strasse 173, 55216, Ingelheim am Rhein, Germany. ${ }^{4}$ Center of Thrombosis and Hemostasis, Johannes Gutenberg University, Medical Center, Mainz, Germany.

Received: 5 July 2012 Accepted: 19 December 2012 Published: 31 December 2012

\section{References}

1. Kearon C, Kahn SR, Agnelli G, Goldhaber S, Raskob GE, Comerota AJ: Antithrombotic therapy for venous thromboembolic disease: American 
College of Chest Physicians Evidence-Based Clinical Practice Guidelines (8th Edition). Chest 2008, 133:454S-545S.

2. Stein PD, Hull RD, Matta F, Yaekoub AY: Anticoagulant therapy for acute venous thromboembolism: what we think we know and what the data show for the timing of recurrent events. Clin Appl Thromb Hemost 2009, 15:609-612.

3. Hansson PO, Sorbo J, Eriksson H: Recurrent venous thromboembolism after deep vein thrombosis: incidence and risk factors. Arch Intern Med 2000, 160:769-774.

4. Heit JA, Mohr DN, Silverstein MD, Petterson TM, O'Fallon WM, Melton LJ: III: Predictors of recurrence after deep vein thrombosis and pulmonary embolism: a population-based cohort study. Arch Intern Med 2000, 160:761-768.

5. Prandoni $P$, Villalta $S$, Bagatella $P$, Rossi L, Marchiori A, Piccioli A, et al: The clinical course of deep-vein thrombosis. Prospective long-term follow-up of 528 symptomatic patients. Haematologica 1997, 82:423-428.

6. Douketis JD, Foster GA, Crowther MA, Prins MH, Ginsberg JS: Clinical risk factors and timing of recurrent venous thromboembolism during the initial 3 months of anticoagulant therapy. Arch Intern Med 2000, 160:3431-3436.

7. van Dongen CJ, Vink R, Hutten BA, Buller HR, Prins MH: The incidence of recurrent venous thromboembolism after treatment with vitamin $\mathrm{K}$ antagonists in relation to time since first event: a meta-analysis. Arch Intern Med 2003, 163:1285-1293.

8. Douketis J, Tosetto A, Marcucci M, Baglin T, Cosmi B, Cushman M, et al: Risk of recurrence after venous thromboembolism in men and women: patient level meta-analysis. Br Med J 2012, 342:d813.

9. Douketis JD, Kearon C, Bates S, Duku EK, Ginsberg JS: Risk of fatal pulmonary embolism in patients with treated venous thromboembolism. JAMA 1998, 279:458-462.

10. Spencer FA, Gore JM, Lessard D, Douketis JD, Emery C, Goldberg RJ: Patient outcomes after deep vein thrombosis and pulmonary embolism: the Worcester Venous Thromboembolism Study. Arch Intern Med 2008, 168:425-430.

11. Murin S, Romano PS, White RH: Comparison of outcomes after hospitalization for deep venous thrombosis or pulmonary embolism. Thromb Haemost 2002, 88:407-414.

12. Kearon C: Natural history of venous thromboembolism. Circulation 2003, 107:122-130

13. Atrial Fibrillation Investigators: Risk factors for stroke and efficacy of antithrombotic therapy in atrial fibrillation. Analysis of pooled data from five randomized controlled trials. Arch Intern Med 1994, 154:1449-1457.

14. Ost D, Tepper J, Mihara H, Lander O, Heinzer R, Fein A: Duration of anticoagulation following venous thromboembolism: a meta-analysis. JAMA 2005, 294:706-715.

15. Schulman S, Beyth RJ, Kearon C, Levine MN: Hemorrhagic complications of anticoagulant and thrombolytic treatment: American College of Chest Physicians Evidence-Based Clinical Practice Guidelines (8th Edition). Chest 2008, 133:257S-298S

16. Kearon C, Gent M, Hirsh J, Weitz J, Kovacs MJ, Anderson DR, et al: A comparison of three months of anticoagulation with extended anticoagulation for a first episode of idiopathic venous thromboembolism. N Engl J Med 1999, 340:901-907.

17. Schulman S, Granqvist S, Holmstrom M, Carlsson A, Lindmarker P, Nicol P, et al: The duration of oral anticoagulant therapy after a second episode of venous thromboembolism. The Duration of Anticoagulation Trial Study Group. N Engl J Med 1997, 336:393-398.

18. Bauersachs R, Berkowitz SD, Brenner B, Buller HR, Decousus H, Gallus AS, et al: Oral rivaroxaban for symptomatic venous thromboembolism. $N$ Engl J Med 2010, 363:2499-2510.

19. Buller HR, Prins MH, Lensin AW, Decousus H, Jacobson BF, Minar E, et al: Oral rivaroxaban for the treatment of symptomatic pulmonary embolism. N Engl J Med 2012, 366:1287-1297.

20. Fiessinger JN, Huisman MV, Davidson BL, Bounameaux H, Francis CW, Eriksson $\mathrm{H}$, et al: Ximelagatran vs low-molecular-weight heparin and warfarin for the treatment of deep vein thrombosis: a randomized trial. JAMA 2005, 293:681-689.

21. Schulman S, Kearon C, Kakkar AK, Mismetti P, Schellong S, Eriksson H, et al: Dabigatran versus warfarin in the treatment of acute venous thromboembolism. N Engl J Med 2009, 361:2342-2352.

22. Schulman S, Kakkar AK, Schellong SM, Goldhaber SZ, Henry E, Mismetti P, et al: A randomized trial of dabigatran versus warfarin in the treatment of acute venous thromboembolism (RE-COVER II). American Society of Hematology Annual Meeting; [https://ash.confex.com/ash/2011/ webprogram/Paper42341.html] Accessed October 22, 2012.

23. Connolly SJ, Ezekowitz MD, Yusuf S, Eikelboom J, Oldgren J, Parekh A, et al: Dabigatran versus warfarin in patients with atrial fibrillation. $N$ Engl J Med 2009, 361:1139-1151

24. Granger CB, Alexander JH, McMurray JJ, Lopes RD, Hylek EM, Hanna M, et al: Apixaban versus warfarin in patients with atrial fibrillation. $N$ Engl J Med 2011, 365:981-992.

25. Patel MR, Mahaffey KW, Garg J, Pan G, Singer DE, Hacke W, et al: Rivaroxaban versus warfarin in nonvalvular atrial fibrillation. N Engl J Med 2011, 365:883-891.

26. Kearon C, Ginsberg JS, Julian JA, Douketis J, Solymoss S, Ockelford P, et al: Comparison of fixed-dose weight-adjusted unfractionated heparin and low-molecular-weight heparin for acute treatment of venous thromboembolism. JAMA 2006, 296:935-942.

27. Prandoni $P$, Carnovali M, Marchiori A: Subcutaneous adjusted-dose unfractionated heparin vs fixed-dose low-molecular-weight heparin in the initial treatment of venous thromboembolism. Arch Intern Med 2004, 164:1077-1083.

28. Cappelleri JC, Fiore LD, Brophy MT, Deykin D, Lau J: Efficacy and safety of combined anticoagulant and antiplatelet therapy versus anticoagulant monotherapy after mechanical heart-valve replacement: a metaanalysis. Am Heart J 1995, 130:547-552.

29. Gitter MJ, Jaeger TM, Petterson TM, Gersh BJ, Silverstein MD: Bleeding and thromboembolism during anticoagulant therapy: a population-based study in Rochester. Minnesota. Mayo Clin Proc 1995, 70:725-733.

30. Linkins LA, Choi PT, Douketis JD: Clinical impact of bleeding in patients taking oral anticoagulant therapy for venous thromboembolism: a metaanalysis. Ann Intern Med 2003, 139:893-900.

31. Spencer FA, Gore JM, Reed G, Lessard D, Pacifico L, Emery C, et al: Venous thromboembolism and bleeding in a community setting. The Worcester Venous Thromboembolism Study. Thromb Haemost 2009, 101:878-885.

32. Carrier M, Le GG, Wells PS, Rodger MA: Systematic review: case-fatality rates of recurrent venous thromboembolism and major bleeding events among patients treated for venous thromboembolism. Ann Intern Med 2010, 152:578-589

33. Nieto JA, Camara T, Gonzalez-Higueras E, Ruiz-Gimenez N, Guijarro R, Marchena PJ, et al: Clinical outcome of patients with major bleeding after venous thromboembolism, Findings from the RIETE Registry. Thromb Haemost 2008, 100:789-796.

34. Lancaster TR, Singer DE, Sheehan MA, Oertel LB, Maraventano SW, Hughes RA, et al: The impact of long-term warfarin therapy on quality of life Evidence from a randomized trial Boston Area Anticoagulation Trial for Atrial Fibrillation Investigators. Arch Intern Med 1991, 151:1944-1949.

35. Gould MK, Dembitzer AD, Sanders GD, Garber AM: Low-molecular-weight heparins compared with unfractionated heparin for treatment of acute deep venous thrombosis. A cost-effectiveness analysis. Ann Intern Med 1999, 130:789-799.

36. Baglin T, Luddington R, Brown K, Baglin C: Incidence of recurrent venous thromboembolism in relation to clinical and thrombophilic risk factors: prospective cohort study. Lancet 2003, 362:523-526.

37. Cushman M, Tsai AW, White RH, Heckbert SR, Rosamond WD, Enright $P$, et al: Deep vein thrombosis and pulmonary embolism in two cohorts: the longitudinal investigation of thromboembolism etiology. Am J Med 2004, 117:19-25.

38. McRae S, Tran H, Schulman S, Ginsberg J, Kearon C: Effect of patient's sex on risk of recurrent venous thromboembolism: a meta-analysis. Lancet 2006, 368:371-378.

39. Palareti G, Cosmi B, Legnani C, Tosetto A, Brusi C, lorio A, et al: D-dimer testing to determine the duration of anticoagulation therapy. $N$ Engl Med 2006, 355:1780-1789.

40. Schulman S, Svenungsson E, Granqvist S: Anticardiolipin antibodies predict early recurrence of thromboembolism and death among patients with venous thromboembolism following anticoagulant therapy. Duration of Anticoagulation Study Group. Am J Med 1998, 104:332-338.

41. van den Belt AG, Sanson BJ, Simioni P, Prandoni P, Buller HR, Girolami A, et al: Recurrence of venous thromboembolism in patients with familial thrombophilia. Arch Intern Med 1997, 157:2227-2232.

42. Ruiz-Gimenez N, Suarez C, Gonzalez R, Nieto JA, Todoli JA, Samperiz AL, et al: Predictive variables for major bleeding events in patients 
presenting with documented acute venous thromboembolism. Findings from the RIETE Registry. Thromb Haemost 2008, 100:26-31.

43. Hutten BA, Prins MH, Gent M, Ginsberg J, Tijssen JG, Buller HR: Incidence of recurrent thromboembolic and bleeding complications among patients with venous thromboembolism in relation to both malignancy and achieved international normalized ratio: a retrospective analysis. J Clin Oncol 2000, 18:3078-3083.

44. Monreal M, Falga C, Valdes M, Suarez C, Gabriel F, Tolosa C, et al: Fatal pulmonary embolism and fatal bleeding in cancer patients with venous thromboembolism: findings from the RIETE registry. J Thromb Haemost 2006, 4:1950-1956

45. Prandoni $P$, Lensing AW, Piccioli A, Bernardi E, Simioni P, Girolami B, et al: Recurrent venous thromboembolism and bleeding complications during anticoagulant treatment in patients with cancer and venous thrombosis. Blood 2002, 100:3484-3488

46. Trujillo-Santos J, Ruiz-Gamietea A, Luque JM, Samperiz AL, Garcia-Bragado F, Todoli JA, et al: Predicting recurrences or major bleeding in women with cancer and venous thromboembolism. Findings from the RIETE Registry. Thromb Res 2009, 123(2):S10-S15.

47. Thorevska N, Amoateng-Adjepong Y, Sabahi R, Schiopescu I, Salloum A, Muralidharan $V$, et al: Anticoagulation in hospitalized patients with renal insufficiency: a comparison of bleeding rates with unfractionated heparin vs enoxaparin. Chest 2004, 125:856-863.

48. Trujillo-Santos J, Prandoni P, Rivron-Guillot K, Roman P, Sanchez R, Tiberio G, et al: Clinical outcome in patients with venous thromboembolism and hidden cancer: findings from the RIETE Registry. J Thromb Haemost 2008, 6:251-255.

49. Louzada ML, Majeed H, Wells PS: Efficacy of low- molecular- weightheparin versus vitamin $\mathrm{K}$ antagonists for long term treatment of cancerassociated venous thromboembolism in adults: a systematic review of randomized controlled trials. Thromb Res 2009, 123:837-844

50. Lyman GH, Khorana AA, Falanga A, Clarke-Pearson D, Flowers C, Jahanzeb $M$, et al: American Society of Clinical Oncology guideline: recommendations for venous thromboembolism prophylaxis and treatment in patients with cancer. J Clin Oncol 2007, 25:5490-5505.

51. Heit JA, Silverstein MD, Mohr DN, Petterson TM, O'Fallon WM, Melton LJ: III: Predictors of survival after deep vein thrombosis and pulmonary embolism: a population-based, cohort study. Arch Intern Med 1999, 159:445-453.

52. Kucher N, Quiroz R, McKean S, Sasahara AA, Goldhaber SZ: Extended enoxaparin monotherapy for acute symptomatic pulmonary embolism. Vasc Med 2005, 10:251-256.

53. Camm AJ, Bounameaux H: Edoxaban: a new oral direct factor xa inhibitor. Drugs 2011, 71:1503-1526.

54. Clinical Trials Idenfifier NCT00643201: Efficacy and Safety Study of Apixaban for the Treatment of Deep Vein Thrombosis or Pulmonary Embolism. ClinicalTrials.gov web site; [http://clinicaltrials.gov/ct2/show/ NCT00643201?term=00643201\&rank=1] Accessed October 22, 2012.

55. Buller HR, Cohen AT, Davidson B, Decousus H, Gallus AS, Gent M, et al: Idraparinux versus standard therapy for venous thromboembolic disease. N Engl J Med 2007, 357:1094-1104.

56. Uchino K, Hernandez AV: Dabigatran association with higher risk of acute coronary events: meta-analysis of noninferiority randomized controlled trials. Arch Intern Med 2012, 172:397-402.

57. Schulman S, Baanstra D, Eriksson H, Goldhaber S, Kakkar A, Kearon C, et al: Dabigatran vs. placebo for extended maintenance therapy of venous thromboembolism. International Society on Thrombosis and Haemostasis; [http://onlinelibrary.wiley.com/doi/10.1111/j.1538-7836.2011.04380_1.x/pdf] Accessed October 22, 2012

58. Schulman S, Eriksson H, Goldhaber SZ, Kakkar AK, Kearon C, Kvamme AM, et al: Dabigatran or warfarin for extended maintenance therapy of venous thromboembolism. International Society on Thrombosis and Haemostasis; [http://onlinelibrary.wiley.com/doi/10.1111/j.15387836.2011.04380 1.x/pdf] Accessed October 22, 2012

59. Eriksson Bl, Smith JJ, Caprini J, Hantel S, Clemens A, Feuring M, et al: Evaluation of the acute coronary syndrome safety profile of dabigatran etexilate in patients undergoing major orthopedic surgery: findings from four Phase 3 trials. Thromb Res 2012, 130:396-402.

60. Deitelzweig SB, Lin J, Kreilick C, Hussein M, Battleman D: Warfarin therapy in patients with venous thromboembolism: patterns of use and predictors of clinical outcomes. Adv Ther 2010, 27:623-633.
61. Rose AJ, Berlowitz DR, Ash AS, Ozonoff A, Hylek EM, Goldhaber-Fiebert JD: The business case for quality improvement: oral anticoagulation for atrial fibrillation. Circ Cardiovasc Qual Outcomes 2011, 4:416-424.

62. Wieloch M, Sjalander A, Frykman V, Rosenqvist M, Eriksson N, Svensson PJ: Anticoagulation control in Sweden: reports of time in therapeutic range, major bleeding, and thrombo-embolic complications from the national quality registry AuriculA. Eur Heart J 2011, 32:2282-2289.

63. Nichol MB, Knight TK, Dow T, Wygant G, Borok G, Hauch O, et al: Quality of anticoagulation monitoring in nonvalvular atrial fibrillation patients: comparison of anticoagulation clinic versus usual care. Ann Pharmacother 2008, 42:62-70

64. Meijer K, Kim YK, Carter D, Schulman S: A prospective study of an aggressive warfarin dosing algorithm to reach and maintain INR 2 to 3 after heart valve surgery. Thromb Haemost 2011, 105:232-238.

65. Darkow T, Vanderplas AM, Lew KH, Kim J, Hauch O: Treatment patterns and real-world effectiveness of warfarin in nonvalvular atrial fibrillation within a managed care system. Curr Med Res Opin 2005, 21:1583-1594.

66. Hylek EM, D'Antonio J, Evans-Molina C, Shea C, Henault LE, Regan S: Translating the results of randomized trials into clinical practice: the challenge of warfarin candidacy among hospitalized elderly patients with atrial fibrillation. Stroke 2006, 37:1075-1080.

67. European Medicines Agency: Questions and answers on the review of bleeding risk with Pradaxa (dabigatran etexilate). European Medicines Agency web site, http://www.ema.europa.eu/docs/en_GB/document_library/ Medicine_QA/2012/05/WC500127768.pdf] Accessed. November 6, 2012.

68. US Food and Drug Administration: FDA drug safety communication: update on the risk for serious bleeding events with the anticoagulant Pradaxa. US Food and Drug Administration web site. 2012. http://www.fda.gov/Drugs/ DrugSafety/ucm326580.htm] Accessed November 6, 2012.

69. Rosencher R, Samama CM, Feuring M, Kleine E, Salmio S, Clemens A, et al: Safety and efficacy of once daily $220 \mathrm{mg}$ dabigatran etexilate in a realworld noninterventional study of more than 5000 patients after total knee or hip replacement. American Heart Association Scientific Sessions web site, 2012; [http://www.abstractsonline.com/Plan/NiewAbstract.aspx? $\mathrm{mID}=2974 \&$ Key $=4911$ efc8-20d6-42ba-a562-4087d52e57e4\&cKey=d643dab90440-4cf3-b861-caf6542d91 bb\&mKey=\%7b14145D5B-F96B-4354-82378F0937744BA4\%7d] Accessed November 6, 2012

doi:10.1186/1477-9560-10-24

Cite this article as: Hass et al:: Treatment of venous thromboembolism effects of different therapeutic strategies on bleeding and recurrence rates and considerations for future anticoagulant management. Thrombosis Journal 2012 10:24.

\section{Submit your next manuscript to BioMed Central and take full advantage of:}

- Convenient online submission

- Thorough peer review

- No space constraints or color figure charges

- Immediate publication on acceptance

- Inclusion in PubMed, CAS, Scopus and Google Scholar

- Research which is freely available for redistribution 